\title{
Evolução da mulher no mercado de trabalho
}

O trabalho vem abordar a conquista do espaço feminino nas lideranças das organizações. Desta forma, a análise realizada, através deste artigo, vem considerar o contexto histórico e cultural do papel social da mulher, que repercute em construções sociais e contextos que ainda dificultam e geram barreiras para a ocupação de certos cargos e funções, bem como, a ascensão de carreira da mulher, no meio empresarial. Logo, este trabalho vem expor as principais barreiras que ainda se apresentam no mercado de trabalho, ao contingente feminino, especificamente, tornando-se necessária a discussão sobre desigualdade de gênero presente na sociedade, dando ênfase ao campo do trabalho. O mesmo estudo também tem como preocupação precípua, destacar e explanar sobre a evolução da mulher no meio social e a ascensão da mesma em suas possibilidades, novos campos de carreira e liderança. Em termos metodológicos, além do levantamento de autores pertinentes ao tema, este trabalho, a partir de pesquisa de campo no estudo de multicasos, se propõe a aplicar questionários com determinadas empresas da região do Cariri, que possuem liderança feminina, para que então, seja possível confirmar ou repensar hipóteses pertinentes à problemática pontuada neste artigo.

Palavras-chave: Feminino; Liderança; Trabalho; Empoderamento.

\section{Evolution of women in the labor market}

The work approaches the conquest of the feminine space in the leaderships of the organizations. In this way, the analysis carried out, through this article, considers the historical and cultural context of the social role of women, which has repercussions on social constructions and contexts that still difficult and create barriers to the occupation of certain positions and functions, as well as the career advancement of women in the business environment. Therefore, this work exposes the main barriers that still exist in the labor market, specifically the female contingent, making it necessary to discuss gender inequality present in society, emphasizing the field of work. The same study also has as its main concern, to highlight and explain about the evolution of women in the social environment and the rise of it in its possibilities, new fields of career and leadership. In methodological terms, in addition to the leverage of authors related to the theme, this work, based on field research in the study of multicasos, proposes to apply questionnaires with certain companies in the Cariri region, which have female leadership, so that, it is possible to confirm or rethink hypotheses pertinent to the problem pointed out in this article.

Keywords: Female; Leadership; Job; Empowerment.

Topic: Recursos Humanos

Reviewed anonymously in the process of blind peer.
Received: 10/01/2019

Approved: 22/04/2019

\section{Yascara Soares Feitosa}

Centro Universitário Dr. Leão Sampaio, Brasil.

http://lattes.cnpq.br/8858668451127698

yascara adm@hotmail.com

\section{Joyce da Silva Albuquerque}

Universidade de Fortaleza, Brasil.

http://lattes.cnpq.br/0230789161277092

joyce@leaosampaio.edu.br
Referencing this:

FEITOSA, Y. S.; ALBUQUERQUE, J. S.. Evolução da mulher no mercado de trabalho. Business Journal, v.1, n.1, p.1-17, 2019. DOI: http://doi.org/10.6008/CBPC2674-6433.2019.001.0005

DOI: 10.6008/CBPC2674-6433.2019.001.0005 


\section{INTRODUÇÃO}

As desigualdades vividas no cotidiano da sociedade, no que se refere às relações de gênero, não se definem apenas a partir do aspecto econômico, estas diferenciações de gênero foram constituídas a partir do cultural e do social. Este último é responsável pela formação e propagação de representações sociais, sobre as funções da mulher e do homem dentro dos variados espaços de convivência, ou seja: na família, na escola, no trabalho; afetando a vida em sociedade. A presença da mulher na economia brasileira se deve a confiança para assumir suas capacidades e lidar com as diversas situações profissionais a fim de obter credibilidade e sucesso na sua vida profissional mesmo em contextos dificultosos na sua trajetória (RABELLO, 2013).

Considerando as transformações sociais e a própria evolução das mulheres no mundo do trabalho, através de lutas sociais, fizeram com que suas características pré-estabelecidas fossem se alterando, passando, por exemplo, a ocuparem postos de trabalho tidos como masculinos. Outro aspecto desta evolução é a forte entrada das mulheres nas universidades, o que produziu um impacto nas carreiras profissionais de prestígio, onde antes predominavam os homens. Hoje as mulheres estão ocupando cargos cada vez mais elevados em empresas e se inserindo de forma consistente nas carreiras técnicas e científicas (NUZZI, 2011).

É certo que ao longo dos anos mudanças importantes têm ocorrido na participação das mulheres no mercado de trabalho. Este processo se consolida diariamente deixando de ser apenas uma oscilação temporária, tornando o processo de incorporação do contingente feminino um fenômeno social contínuo e persistente (GARCIA et al., 2012). Todavia, considerando o contexto do papel social da mulher nas décadas passadas que repercutem em uma série de construções sociais e contextos que ainda dificultam e geram barreiras para a ocupação de certos cargos e funções, bem como, a ascensão de carreira da mulher, no meio empresarial, surgem como questões norteadoras deste trabalho, ao questionar: se mesmo com toda a participação das mulheres no mercado, se elas ainda encontram dificuldade de assumir papéis de liderança? As mesmas recebem rendimento menor que os homens mesmo executando as mesmas funções? Apresentam maiores chances de ficarem desempregadas?

No intuito de versar sobre esta problemática exposta acima, o trabalho tem como objetivo geral, analisar a conquista do espaço feminino nas lideranças das organizações, tendo como suporte metodológico o estudo de multicascos, onde nos específicos é possível analisar quais as principais dificuldades enfrentadas para assumir cargos de liderança nas organizações, analisar se a faixa salarial é a mesma de homens que exercem a mesma função, além de discutir e pontuar por meio de referencial teórico como o papel social histórico da mulher vem se transformando nas gerações.

A escolha e relevância da temática de pesquisa se dá pela percepção do crescimento da mulher nas organizações, bem como, sua ascensão nos níveis de conhecimento científico, ocupando novos espaços ao longo dos anos como será tratada na análise histórica do referencial teórico. Logo, tem-se, como importância deste escrito, a ilustração das capacidades de participação feminina na sociedade, dando ênfase ao mercado 
de trabalho, acompanhada por avanços importantes de seus empregos e na diversificação de suas oportunidades de trabalho, porém, também se faz necessário dar ênfase para as muitas barreiras ainda existentes e compreendê-las.

\section{REVISÃO TEÓRICA}

\section{Evolução da mulher no mercado de trabalho}

Ao refletir sobre o crescimento e emancipação profissional, fruto do aumento da escolaridade e da possibilidade de novos projetos profissionais, abre a possibilidade de se discutir, mais profundamente, o papel da mulher e do homem na família e na sociedade, bem como a necessidade de compartilhar de forma mais igualitária as tarefas do lar, da educação e da criação dos filhos (RABELLO, 2013).

Em virtude das funções pré-definidas aos gêneros, anteriormente, considerando o contexto histórico social de uma época anterior, as mulheres não poderiam competir com os homens, visto que tinham papéis sociais distintos a cumprir e, principalmente, características próprias à sua natureza feminina. Adequar o tipo de trabalho a cada sexo foi, assim, a maneira encontrada nas sociedades ocidentais para manter a harmonia familiar e no mercado de trabalho. Deste modo, foram se estabelecendo e naturalizando as profissões consideradas masculinas e femininas. "Mensagens veiculadas pelos meios de comunicação enfatizavam a imagem da 'rainha do lar', exacerbando-se a mistificação do papel da dona-de-casa, esposa e mãe. Deste modo, o trabalho externo da mulher era desvalorizado, tido como suplementar ao do homem" (ALVES, 2007).

Nesse contexto, a mulher sempre foi rotulada de sexo frágil, submissa, ou mesmo incapaz de enfrentar e vencer grandes desafios, de modo que suas responsabilidades eram limitadas a serviços domésticos, ou seja, a mulher era boa para cuidar do lar. Entretanto cada vez mais vem se consolidando a indiscutível presença feminina no mundo dos negócios, provando que a mulher é capaz de estar presente no lar e na empresa, alcançando resultados expressivos em ambas as funções.

Paralelamente a evolução feminina, com a inserção da mulher no mercado de trabalho, persiste barreiras socialmente construídas que reproduzem padrões de dominação e subordinação, o qual atingem o público feminino. Mesmo que, ao analisar o cenário contemporâneo da mulher nas empresas, estudos sociais comprovam que as mulheres tendem a adotar estilos de liderança mais democráticos, de cooperação e de transparência, trazendo maiores resultados para as organizações em termos de desempenho financeiro e melhoria das relações de trabalho (GONÇALVES, 2008).

De acordo com Alves (2013), a idealização de um modelo ideal de família no qual reafirmava-se o espaço privado, doméstico, como natural às mulheres, delimitado pelas demandas da maternidade e efetivação das capacidades de trabalho femininas, atrelado a um discurso médico que buscava nas diferenças biológicas evidenciar que a mulher era mais frágil e inferior em relação ao homem, contribuiu para a construção social do feminino e masculino e do que é próprio para cada um dos gêneros na sociedade. Hirata et al. (2007) discutem a problemática da divisão sexual do trabalho:

A divisão sexual do trabalho é a forma de divisão do trabalho social decorrente das relações sociais entre os sexos; mais do que isso, é um fator prioritário para a sobrevivência da 
relação social entre os sexos. Essa forma é modulada histórica e socialmente. Tem como características a designação prioritária dos homens à esfera produtiva e das mulheres à esfera reprodutiva e, simultaneamente, a apropriação pelos homens das funções com maior valor social adicionado (HIRATA et al., 2007).

No contexto atual, a mulher desenvolve suas capacidades e funções profissionais junto aos afazeres domésticos na maioria dos casos, uma questão que cabe problematização. Nesse sentido, o movimento feminista passou a reivindicar "funções iguais, salários e direitos iguais; igualdade de oportunidades no acesso ao mercado de trabalho e à ascensão e aprimoramento profissional [...] conscientização da mulher de seu próprio valor e da necessidade de que ela se coloque como agente da sua liberação" (ALVES, 2007).

Ao abordar o movimento feminista, Lauschner (2011) vem tratar que este movimento traz à tona a luta contra ações de manipulação e dominação masculina, uma vez que a mulher por muitos anos foi colocada em plano secundário em que o marido controlava seus atos externos, seus hábitos, suas relações, enfim, sua vida. Esta relação trouxe para as mulheres uma força, cada vez maior, para lutar, e isto a levou a assumir uma dupla jornada, no momento em que passa a atuar na esfera pública, ao mesmo tempo que ocasiona um confronto interno e social, pois, as mesmas, sofrem constantemente com as represálias e questionamentos sobre onde realmente é o seu lugar, tendo em vista que sua vida profissional tomou o tempo que era para sua família. Algumas delas chegaram a desistir de sua vida profissional para cuidar de sua família.

\section{Barreiras e ascensão da mulher no mercado de trabalho}

Este tópico vem abordar as dificuldades de romper com as históricas limitações impostas. Há os obstáculos ao acesso feminino aos cargos mais elevados e qualificados do ponto de vista da valorização do trabalho e/ou cargos de chefia, onde estão presentes a concentração do poder e os melhores salários. Por outro lado, há também uma luta pela superação da submissão na contemporaneidade e ampliação de possibilidades:

Sem perder de vista que a nova realidade que se apresenta no universo feminino e consoante as crescentes exigências administrativo-organizacionais e de mercado, a elevação da participação feminina nos mais diversos setores e uma nova proposta de liderança, que entende como ilógica a segregação da mulher a cargos diretivos, são razões que contribuem para um aumento das oportunidades às executivas mulheres (KANAN, 2010).

O aumento da participação feminina no mercado de trabalho tem contribuído bastante para a redução das diferenças entre homens e mulheres economicamente ativos. Para Lauschner (2011):

As mudanças e conquistas vivenciadas pelo sujeito feminino que passa por um significativo reconhecimento social, embora ainda não haja equiparação salarial entre mulheres e homens. Essas conquistas são frutos da organização política das mulheres que tem no movimento feminista seu ponto central (LAUSCHNER, 2011).

A fragilidade então propagada pela sociedade como própria da mulher é reafirmada pela submissão do feminino ao masculino. A submissão, na maioria das vezes, faz com que muitas mulheres também acreditem neste discurso da fragilidade. Fatores culturais contribuem, de forma muito significativa, para 
propagar e reforçar a crença de que o homem é superior à mulher. Ademais, na visão de Cavedon et al. (2005):

A mulher ainda tem gravado em seu inconsciente o papel que lhe foi atribuído por décadas e sente-se culpada se não consegue equilibrar os seus papéis de mulher, mãe e profissional. A independência no âmbito do simbólico ainda não ocorreu. O esgotamento físico e mental resultante de uma sobrecarga em face de uma dupla ou tripla jornada de trabalho é uma realidade que merece maior atenção (CAVEDON et al., 2005).

Considerando algumas famílias que são chefiadas por mulheres, nota-se, que a presença de filhos pequenos não parece impedir a maioria das mulheres de procurar trabalho, mas dificulta o seu acesso a uma ocupação, seja por restringir sua escolha de trabalho por um local mais próximo de sua residência e/ou por um tipo de jornada de trabalho menor ou mais flexível ou, ainda, pelo lado do empregador, por preferir contratar mulheres que não possuam filhos menores (RABELLO, 2013). Mesmo com as evoluções e conquistas da mulher nos últimos tempos no mercado de trabalho, ela ainda está em uma condição de desvantagem em relação aos homens, pois continua existindo preconceito, discriminação e desigualdades, principalmente em relação à faixa salarial.

Pois, seguindo o pensamento de Neves (2013), a inserção da mulher no mercado de trabalho ainda remete a desafios e conflitos relacionados a preconceitos, acúmulo de atividades, assim como a própria auto superação feminina, quanto a sua capacidade de desempenhar, assim como os homens, atividades vistas como exclusivamente masculinas. A articulação entre trabalho profissional e trabalho familiar e doméstico (dupla jornada de trabalho feminina) requer uma reformulação do uso de tempos e espaços, pois as mulheres vivem mais intensamente a tensão da pluralidade dos tempos, o que faz com que, muitas vezes, busquem exercer atividades produtivas que permitam a flexibilidade dos tempos e que as unam em espaços como forma de reduzir preconceitos e conflitos, que mesmo assim existem.

Um exemplo muito significativo da tensão entre trabalho remunerado e trabalho reprodutivo vem do caso das famílias chefiadas por mulheres. Em todo o mundo, inclusive no Brasil, o número de famílias deste tipo tem crescido de modo expressivo. Não se trata de fenômeno necessariamente negativo, já que, em muitos casos, a maior autonomia econômica da mulher pode lhe ajudar a sair de uma situação familiar de abuso e risco (como no caso das vítimas da violência doméstica). Mas as desigualdades de gênero fazem com que homens e mulheres experimentem de forma diferenciada situações de vulnerabilidade e tenham estratégias diferentes para confrontá-las (CUNHA et al., 2009).

Nas últimas décadas, nossa sociedade vem avançando ao quebrar significativamente paradigmas seculares e assim diminuindo as desigualdades impostas a homens e mulheres que eram consideradas como 'naturais', visto que são culturais. As mulheres passaram a ocupar espaços tidos socialmente como masculinos, enquanto alguns homens passaram a exercer funções ditas como femininas, a partir da superação contemporânea de padrões culturais engessados. São contribuintes para essa modificação os movimentos feministas e o aumento da presença feminina nos espaços públicos, somado à diminuição da taxa de fecundidade por mulher e a expansão da escolaridade e do acesso às universidades (RODRIGUES, 2010).

A participação das mulheres no mercado de trabalho brasileiro teve um aumento considerável nas últimas décadas, no entanto, os homens ainda continuam sendo os maiores responsáveis pelo quadro de 
funcionários das empresas (TREVISAN, 2014). A busca pelo seu espaço e a luta para diminuir a descriminação de gênero, faz com que a mulher caminhe por espaços por ela nunca percorridos. A mulher tem buscado melhorar seu nível educacional para se qualificar e diminuir a desigualdade de gênero (MAIO et al., 2012).

De acordo com Cunha et al. (2009), as lutas dos movimentos feministas contra a desigualdade de gênero são de grande importância para a autonomia feminina nos tempos atuais, por lutarem em busca da valorização da mulher como ser igualitário ao homem nos domínios políticos e sociais visando à redução da submissão feminina, imposta inclusive no trabalho, porém ainda é possível observar no cotidiano algumas barreiras próprias do contexto atual.

As conquistas das mulheres no mercado de trabalho se deram pelo empenho, organização e luta do movimento feminista, que exerce forte liderança nos embates em busca dos direitos das mulheres no mundo. Desde a efervescência das lutas a partir dos anos 1960, o feminismo passa a ser visto como um movimento social que vem trazendo contribuições consideráveis para a história das mulheres. "Este redirecionamento na agenda política se deu em meio a um contexto de crítica ao estatismo e ascensão da sociedade civil organizada como esfera potencialmente emancipatória, período marcado pela emergência dos chamados novos movimentos sociais" (CUNHA et al., 2009).

Segundo pesquisas do IBGE no ano de 2004, o total de pessoas ocupadas no Brasil era de 84.546.294. Deste total, $41,8 \%$ são mulheres, o que revela um aumento de sua participação na população economicamente ativa, pois, no início da década de 1940, essa participação era de 35\%. Dados presentes na pesquisa de emprego do IBGE evidenciam, que em janeiro de 2008, havia cerca de 9,4 milhões de mulheres trabalhando nas seis regiões metropolitanas de abrangência da pesquisa (Recife, Salvador, Belo Horizonte, Rio de Janeiro, São Paulo e Porto Alegre). É pertinente considerar que esse número é ascendente, uma vez que, em 2003 , elas representavam $40,1 \%$. Apesar disto, mesmo sendo maioria na população total e a disputa do crescimento no seu nível de ocupação, as mulheres ainda são minoria no mercado de trabalho (KANAN, 2010).

Nesta perspectiva de pensamento que destaca a inserção da mulher no mercado de trabalho, é possível pensar essa ascensão apesar das barreiras enfrentadas no mercado de trabalho, através de uma mudança social:

Esse processo somente promoverá mudanças profundas na sociedade, se no âmbito coletivo, as possibilidades de participação das mulheres nos níveis decisórios mais elevados sejam ampliadas, construindo junto com os demais, as condições necessárias para emancipação dos sujeitos sociais e a pena participação necessárias para emancipação dos sujeitos sociais e a plena participação destes, na definição dos rumos de uma sociedade mais justa e igualitária (SPRICIGO, 2017).

Para que as mulheres possam ocupar lugares e papéis diferenciados no mundo empresarial é preciso romper barreiras, inclusive culturais, além da falta de tempo para qualificação profissional, pouco reconhecimento e estereótipos relacionados a gênero. Há formas velhas e novas formas de discriminação, às quais a mulher está exposta. Pois, além das diferenças salariais, há obstáculos ao acesso a cargos mais elevados e qualificados do ponto de vista da valorização do trabalho e/ou cargos de chefia, nestes estão presentes a concentração do poder e os melhores salários. Considerando a evolução feminina no decorrer 
do tempo, apesar dessas barreiras já destacadas na argumentação deste tópico, a motivação para o trabalho para além do doméstico, tem-se constituído como uma das mais notáveis características da mulher moderna.

\section{Transformação social e liderança feminina no contexto empresarial contemporâneo}

A incorporação do contingente feminino se tornou um fenômeno social contínuo e persistente. A atividade feminina no Brasil teve um aumento significativo nas últimas décadas, a taxa de participação de mulheres, entre 15 e 59 anos de idade, aumentou de 52,5\% (1992) para 61\% (2012), segundo o que afirma Barbosa (2014). A seguir D'Alonso vem explanar a expansão de campos ocupados por mulheres: “As mulheres deixaram de ser meras donas de casa e passaram a ser, não somente mãe, esposa e também operária, enfermeira, professora, arquiteta, juíza, motorista de ônibus, bancária, diversificadas profissões, ocupando um cenário que antes era masculino" (DALONSO, 2008).

Nas últimas décadas o papel da mulher na economia e na sociedade, como um todo, tem passado por rápidas e significativas transformações. Com as mudanças, os lares passaram a ser chefiados por mulheres, casais começaram a dividir compromissos, responsabilidades e, como resultado, a mulher se tornou cada vez mais participativa econômica e socialmente.

O trabalho feminino passa a integrar crescentemente a estrutura econômica a sociedade capitalista. Nessa perspectiva, Bruschinie Lombardi (2012,) fazem uma análise baseada nos resultados e conquistas dos movimentos feministas, associando à ascensão de carreiras do contingente feminino: "o ingresso das mulheres nessas áreas cientificas e artísticas tem-se dado na esteira dos movimentos políticos e sociais deflagrados nas décadas de 60 e 70 do século XX. Incluindo o movimento feminista, a mudança de valores culturais e a expansão da escolaridade das mulheres [...]".

Silva et al. (2005) vem destacar que o crescimento da participação feminina nos últimos cinquenta anos é explicado por fatores econômicos e culturais. Logo, pontua que o avanço da industrialização transformou a estrutura produtiva, a continuidade do processo de urbanização e a queda das taxas de fecundidade, proporcionando um aumento das possibilidades das mulheres encontrarem postos de trabalho na sociedade. "Sempre que se buscar entender o papel da mulher na sociedade, é necessário conhecer sua história, para então entender a formação de sua identidade, de seus grupos sociais, seu posicionamento no contexto familiar e no mercado de trabalho" (BAYLÃO et al., 2014). Desse modo, Pinheiro (2012) traz uma percepção sociológica sobre este fenômeno em análise:

Para Karl Marx (2008), a história da produção e reprodução do ser social, ou seja, sua realização, só efetiva-se pelo trabalho. A atividade profissional apresenta-se como gênese da realização do ser social, condição para sua existência, constituindo assim, o ponto de partida para sua humanização. Dentro deste contexto, a cidadã só está completamente inserida através da atividade laboral, onde se realiza como pessoa. Esse aspecto é muito interessante porque marca a evolução qualitativa da mão-de-obra feminina no Brasil nos últimos anos. Se antes as mulheres no Brasil eram em sua maioria domésticas e pequenas artesãs, a partir da década de 70 conquistaram espaço em diversas profissões tidas até então como masculinas (PINHEIRO, 2012).

Numa perspectiva estereotipada, a mulher assume a condição de 'provedora', quando lhe falta alternativa, quando as circunstâncias impedem que exerça seu papel fundamental de 'cuidadora'. Daí 
decorre a imagem estereotipada da mulher como alguém com baixo compromisso com o trabalho e tendente a abandonar a atividade econômica assim que possível.

A noção de inserção 'secundária' das mulheres está na raiz do preconceito de gênero, o estereótipo impacta de forma decisiva a vida profissional das mulheres: torna instável e interrompida sua trajetória ocupacional, reduz a importância social de sua renda, impede ou dificulta sua ascensão a posições de maior hierarquia (ABRAMO, 2010).

Ao longo da história, as mulheres assumiram o papel 'natural' de prover cuidados, e os homens, por sua vez, encarregaram-se do sustento financeiro do lar, o que delineou um modelo de homens provedores e mulheres cuidadoras. Isso contribuiu com a crença social de que a família é responsabilidade da mulher e o trabalho, por seu turno, do homem. Tal fato perpetuou, culturalmente, a dicotomia entre a vida pública e privada entre os sexos, pois para cada parte estaria reservado o seu espaço. A vida pública para os homens, e a vida doméstica para as mulheres (PASSOS et al., 2017). Ainda nas palavras dos autores, ao abordar esta perspectiva:

Devido a essas atribuições sociais, a trajetória das mulheres é marcada por pressões e opressões dentro e fora dos seus lares. A vivência cotidiana no cuidado da família foi acompanhada da ausência de atuação no mundo produtivo, constituindo um modelo no qual era negado indiretamente às mulheres a existência fora do lar. Assim, com base nos papéis socialmente instituídos, delinearam-se funções assimétricas entre os sexos, consagrando uma divisão sexual do trabalho que pode ser considerada desigual e desfavorável para as mulheres (PASSOS et al., 2017).

Assim, o grande poder do discurso é a naturalização das relações de gênero e a divisão sexual do trabalho que ele produz. Trata-se do processo que legitima e torna inquestionáveis, evidentes em si, o significado socialmente estabelecido e a separação entre categorias como 'mercado de trabalho' e 'lar'. A entrada da mulher no âmbito do trabalho traz repercussões na organização e na estrutura de funcionamento familiar, levando à proposição de novas configurações, arranjos familiares com interferências diretas na dinâmica familiar. Um dos principais desafios para a mulher está em conciliar tempo para tarefas domésticas, acadêmicas, trabalho externo (e ainda poder permanecer com os filhos, caso houver), em um contexto em que a configuração familiar tem-se delineado diferentemente da estrutura familiar tradicional (SIMÕES et al., 2012).

Logo, se constroem as diversas representações sociais que contribuem à configuração das desigualdades entre homens e mulheres no mercado de trabalho, visto que como já foi explanado, há elementos que estruturam e reproduzem as hierarquias entre homens e mulheres, os padrões de discriminação e subordinação de gênero no mercado de trabalho. Nesta perspectiva, é fundamental desvelar os mecanismos que produzem diferenciação, onde não uma superação completa, apesar das mudanças coexistentes. Esta discussão não inclui apenas o trabalho como também outras dimensões da vida social. "A explicação para esta desigualdade está na forma como se constroem as relações entre o masculino e o feminino na sociedade, relegando a este um diminuto espaço de participação, o que se constata com a análise histórica da inserção da mulher no mercado de trabalho" (ALVES; et al., 2009). 
Segundo Cunha et al. (2009), "as mulheres ainda são tratadas como invisíveis por parte das políticas de desenvolvimento e trabalho. Ao não considerarem determinantes de gênero, políticas econômicas tornam mulheres pobres em termos de recursos materiais, conhecimento e tempo". Os estereótipos desvalorizam a força de trabalho feminina e estão presentes no imaginário social e consequentemente, no empresarial. Sendo que estes pensamentos e representações se transformam (ou não) com o tempo.

A legislação trabalhista brasileira contempla uma série de normas que visam repelir possíveis discriminações nas relações de trabalho. Não obstante, os dados sociais revelam que determinadas categorias e grupos sociais como os negros e as mulheres ainda são sistematicamente discriminados" (ALVES et al., 2009).

Desse modo, é possível identificar uma série de problemas enfrentados pelas mulheres no mundo do trabalho:

a) salários menores do que os dos homens por trabalhos equivalentes;

b) dupla jornada, produto de uma divisão sexual do trabalho que ainda prevê que todo o gerenciamento da vida doméstica é trabalho feminino;

c) deficiências nas políticas sociais, o que impede o acesso aos serviços de apoio familiar, como creches, refeitórios e outros equipamentos sociais para mulheres de menor renda;

d) menores chances de capacitar-se profissionalmente nas áreas rentáveis, cujas vagas são destinadas majoritariamente aos homens (as profissões vistas como extensões do trabalho reprodutivo e, portanto, com remunerações menores são ainda as que oferecem maiores chances às mulheres);

e) falta de voz nos espaços de decisão e de poder para negociar acordos coletivos de trabalho, em razão das desigualdades de gênero nas próprias relações sindicais; etc. (GOMES, 2005).

O crescimento consistente da presença das mulheres na esfera econômica demonstra um movimento diverso daquele, tradicionalmente verificado na sociedade até agora. Não se trata apenas de trabalho para complementar a renda familiar, trata-se, antes, de uma mudança social de grandes proporções, pois envolve transformações na expectativa de vida pessoal, nas relações familiares, nas demandas por serviços públicos. Sobre a transformação do trabalho feminino, podemos perceber:

0 primeiro desses fatores diz respeito à possibilidade de se pagar menos pelo mesmo trabalho - embora se notem pequenos avanços na redução da diferença salarial, devidos ao crescimento do nível de instrução feminina (principalmente nos países mais desenvolvidos). $\mathrm{O}$ segundo fator refere-se às habilidades de relacionamento, mais desenvolvidas na mulher e cada vez mais necessárias em uma economia informacional em que o gerenciamento de recurso é menos importante do que o gerenciamento de pessoas. Um terceiro fator, o mais importante, é a flexibilidade feminina como força de trabalho; isto é, a nova economia exige flexibilidade quanto ao horário e à entrada e saída do mercado de trabalho. (CASTELLS, 1999)

Torna-se importante destacar que o ingresso da mulher no mercado de trabalho não se dá apenas na condição de empregada, visto que ela também é empregadora. A educação tem sido a via pela qual a mulher pode abreviar seu ingresso, com segurança, nas carreiras profissionais. $O$ atual contexto tende a valorizar o conhecimento gerado pelas pessoas, pressupõe-se que aqueles que detêm qualidades como capacidade para inovar e possuem intuição estão mais bem preparados para ocupar cargos de chefia e liderança dentro de todo tipo de organização, pois não se trata apenas de competência técnica e intelectual, mas, sobretudo, de competência interpessoal. Chiavenato (2008) destaca que a liderança é "um fenômeno tipicamente social que ocorre exclusivamente em grupos sociais e nas organizações, exercida como uma 
influência interpessoal em uma dada situação e dirigida através do processo de comunicação humana para a consecução de um ou mais objetivos específicos".

Considerando os contextos de transformação social, apesar das barreiras discutidas, a identificação das mesmas pela sociedade, a luta dos movimentos sociais e o amplo debate sobre estas questões de gênero, vem possibilitando caminhos de conquista para a mulher, de reconhecimento do seu potencial gestor, da valorização da sua força de trabalho ao desenvolver sua autonomia no empreendedorismo e na ocupação de cargos de responsabilidade.

\section{METODOLOGIA}

Este trabalho trata-se de uma pesquisa de campo reflexiva ao utilizar-se de fontes bibliográficas sobre a temática da mulher no mercado de trabalho, considerando uma análise exploratória do histórico social para desenvolver percepções baseadas em autores, para dissertar sobre o cenário empresarial contemporâneo. Logo, se trata de uma pesquisa de abordagem qualitativa e bibliográfica em que o conteúdo de embasamento teórico reflexivo foi extraído de livros, revistas eletrônicas e artigos publicados para abordar o crescimento da mulher no mercado de trabalho.

Esta abordagem qualitativa como método de investigação científica se foca no caráter subjetivo do objeto analisado, estudando as suas particularidades e experiências individuais, por exemplo. A pesquisa qualitativa não se preocupa com representatividade numérica, mas, sim, com o aprofundamento da compreensão de um grupo social, de uma organização etc. Para Minayo (2012), a pesquisa qualitativa trabalha com o universo de significados, motivos, aspirações, crenças, valores e atitudes, o que corresponde a um espaço mais profundo das relações, dos processos e dos fenômenos que não podem ser reduzidos à operacionalização de variáveis.

A pesquisa do tipo descritiva busca descrever um fenômeno para o estudo, utilizando técnicas padronizadas de coleta de dados, tais como o questionário aplicado na pesquisa de campo deste trabalho, a mesma permite abranger as características de um indivíduo, uma situação ou grupo, bem como desvendar a relação entre os eventos (GIL, 2008). Desse modo, a pesquisa deste tipo permite a captura do cenário da situação em estudo.

A pesquisa foi realizada por meio de uma entrevista, Quadro 1, com um roteiro estruturado contendo onze perguntas que foram aplicadas a quatro mulheres empreendedoras da região do Cariri, com a finalidade de analisar a conquista do espaço feminino nas lideranças das organizações. A amostra teve a determinação por acessibilidade, todas as pesquisadas possuem empresas atuantes na cidade de Crato/CE e Juazeiro do Norte/CE.

Os dados coletados na entrevista foram anotados no momento da ocorrência da mesma, não havendo a necessidade de gravação. Os dados coletados foram tratados por meio de análise de conteúdo, dialogando com os autores da bibliografia.

\section{RESULTADOS}


A partir da coleta dos dados em campo é possível conceber o cenário atual do feminino no mercado de trabalho, ao identificar diversos elementos pontuados pelos autores, no referencial teórico, que contemplam as conquistas e dificuldades, de ser mulher, no contexto social e empresarial contemporâneo. A mulher conseguiu se inserir em novos espaços e cargos no trabalho, antes ocupados apenas por homens por determinações culturais e ainda pela dificuldade em ascender na vida acadêmica, fator fundamental para capacitação profissional e abertura de oportunidades de carreira. Assim, seguindo o pensamento de Nuzzi (2011) e outros autores, a mulher vem crescendo processualmente no decorrer da décadas, enfrentando as barreiras culturais diariamente, junto a soma de outras atividades para gerir seu tempo.

Considerando toda a explanação do estudo sobre a inserção da mulher no mercado de trabalho e sua ascensão, em entrevista foi perguntado, para as entrevistadas, se elas conseguiam perceber os avanços femininos nas empresas.

Tabela 1: Conquista do espaço feminino nas lideranças das organizações.

\begin{tabular}{|l|l|}
\hline \multicolumn{2}{|l|}{ Você consegue perceber a conquista do espaço feminino nas lideranças das organizações? } \\
\hline Entrevistada 1 & $\begin{array}{l}\text { Sim, ainda que pouco, mas posso dizer que é bem inferior ao masculino, devido a uma resistência até cultural, } \\
\text { mas acredito que já houve avanços. }\end{array}$ \\
\hline Entrevistada 2 & $\begin{array}{l}\text { Com certeza, a cada dia a mulher vem ganhando seu espaço em lideranças, principalmente quando se trata de } \\
\text { organizar e liderar. }\end{array}$ \\
\hline Entrevistada 3 & $\begin{array}{l}\text { Percebo que as mulheres conseguem esse espaço, mas há muito o que conquistar, ter mais oportunidade para } \\
\text { as mulheres exercer tarefas que são exercidas somente por homens. Ainda há muito o que melhorar! }\end{array}$ \\
\hline Entrevistada 4 & $\begin{array}{l}\text { Percebo essa conquista, mas também tem as individualidades e oportunidades de cada pessoa para alcançar } \\
\text { esse espaço. }\end{array}$ \\
\hline
\end{tabular}

A partir das primeiras respostas acima, é possível perceber o reconhecimento dos avanços femininos no mercado de trabalho pela fala das entrevistadas, mas que, porém, há muitas conquistas nesse meio que são necessárias para sua inserção nos espaços de trabalho, inclusive nas lideranças. Andrade (2016) enfatiza que a discriminação é provavelmente a maior barreira enfrentada pela mulher no mundo do trabalho, fato diretamente relacionado ao gênero, alertando ainda para os altos índices de assédio - realidade que pende mais para a mulher, por causa da terrível visão de 'objeto sexual', surgindo várias invasões de espaço e 'cantadas' inapropriadas em seu ambiente de trabalho, que, por vezes, surgem do próprio chefe ou até mesmo dos colegas de trabalho, pois, a visão de submissão feminina é inquestionável nessas situações, ela ainda é forte e corriqueira. Com base no preconceito que a mulher ainda lida em seu convívio de trabalho, foi feita a seguinte pergunta:

Tabela 2: Preconceito com as mulheres no mercado de trabalho.

\begin{tabular}{|l|l|}
\hline \multicolumn{2}{|c|}{ Você percebe algum preconceito com as mulheres no mercado de trabalho? } \\
\hline Entrevistada 1 & $\begin{array}{l}\text { Sim, principalmente se tratando da parte física, idade, escolaridade, cor, se possui filhos, são muitas as formas } \\
\text { de se ter preconceito com a mulher. }\end{array}$ \\
\hline Entrevistada 2 & Infelizmente sim, só que a mulher ultimamente não está mais se sentindo inferior aos demais. \\
\hline Entrevistada 3 3 & $\begin{array}{l}\text { Muito preconceito, quando a mulher exerce tarefas 'ditas' de homem, eles ficam esnobando, sendo que a } \\
\text { mulher muitas vezes executa essas atividades com mais facilidade, responsabilidade e criatividade do que eles... } \\
\text { mais pontuais e comprometidas. Ainda há sim preconceitos a serem superados. }\end{array}$ \\
\hline Entrevistada 4 $4 \begin{array}{l}\text { Sim, trabalho na área da Saúde, percebo isso quando se trata da classe médica que ainda predomina homens } \\
\text { onde eu trabalho, dito isto, há muitas situações em que os homens se sentem superiores, acima de todos, } \\
\text { principalmente da enfermagem por predominar mulheres. Hoje acredito que avançamos bastante porque, nós } \\
\text { mulheres, estamos estudando mais e conseguimos discutir de 'igual para igual', por causa de mestrado, } \\
\text { doutorado, pós-doutorado. Temos uma evolução bem significativa o que aconteceu em decorrência do acesso } \\
\text { aos estudos. }\end{array}$ \\
\hline
\end{tabular}


Ao analisar as respostas anteriores fica evidente os preconceitos existentes em relação a mulher no mercado de trabalho, ao questionarem sua competência e autonomia, mesmo com os avanços, principalmente nos níveis de escolaridade das mulheres. Os estereótipos desvalorizam a força de trabalho feminina, o trabalho da mulher ainda é visto como secundário e complementar a renda familiar, de acordo com a argumentação de Cunha et al. (2009). Há outro aspecto que é fundamental salientar, que é a dupla/tripla jornada da mulher, a partir disso foi questionado às entrevistadas:

Tabela 3: Sobrecarga por conciliar atividades domésticas e o trabalho formal.

\begin{tabular}{|l|l|}
\hline Você já se sentiu sobrecarregada por conciliar atividades domésticas e o trabalho formal? \\
\hline Entrevistada 1 & Sim. \\
\hline Entrevistada 2 & $\begin{array}{l}\text { Sim, não tem como não se sentir sobrecarregada, pois a mulher realiza muitas funções ao mesmo } \\
\text { tempo, mas consegue com êxito. }\end{array}$ \\
\hline Entrevistada 3 & $\begin{array}{l}\text { Muito sobrecarregada, ao cuidar dos parentes, da casa, dos filhos e do estudo, porém exerço todas estas } \\
\text { tarefas com dedicação... }\end{array}$ \\
\hline Entrevistada 4 & $\begin{array}{l}\text { Sempre, porque sou mãe, sou mulher, profissional e hoje sou empresária. Tenho essa empresa que } \\
\text { administro... a todo estante você se sente sobrecarregada, além disso tem a vida acadêmica, os } \\
\text { trabalhos de mestrado e a perspectiva de entrar no doutorado, alcançar novo horizontes. }\end{array}$ \\
\hline
\end{tabular}

Como foi abordado pelos autores Rabello, Neves, Alves, Lauschner, entre outros, há claramente uma sobrecarga sob as mulheres, por ter para si atribuídas as tarefas domésticas e o cuidado com os filhos, além de dificuldades de compreensão do cônjuge para conciliar estas tarefas com a vida profissional e/ou acadêmica. As dificuldades destacadas pelo levantamento bibliográfico são confirmadas pelas respostas das entrevistadas. Ao considerar o crescimento feminino nas lideranças contemporâneas, se fez necessário a seguinte pergunta:

Tabela 4: Dificuldades enfrentadas para assumir cargos de lideranças nas organizações.

\begin{tabular}{|l|l|}
\hline \multicolumn{2}{|c|}{ Quais as principais dificuldades que você já enfrentou para assumir cargos de lideranças nas organizações? } \\
\hline Entrevistada 1 & A compreensão por parte do conjugue, conciliar tarefas domésticas e familiar. \\
\hline Entrevistada 2 & Gosto do que faço, o que ajuda muito e possibilita assumir sem muitos problemas. \\
\hline Entrevistada 3 & O julgamento das pessoas e o medo de aproximação de uma mulher independente, proativa... \\
\hline Entrevistada 4 & $\begin{array}{l}\text { Preconceito, estranhamento/resistência à mulher na função de líder, atribuir o sucesso a fatores } \\
\text { externos, falta de confiança... }\end{array}$ \\
\hline
\end{tabular}

Em continuidade da linha de raciocínio sobre as barreiras vencidas pelas mulheres no cotidiano, a resposta das entrevistadas na pergunta a seguir, elencou diversos aspectos identificados por Gomes (2005), como problemas enfrentados pelas mulheres no mundo do trabalho com relação a sua dupla jornada e gestão de tempo para estudar, trabalhar e cuidar do lar. Logo, a pergunta realizada foi:

Tabela 5: Conciliação entre atividades domésticas e filhos e o desenvolvimento de carreira.

\begin{tabular}{|l|l|}
\hline \multicolumn{2}{|c|}{$\begin{array}{l}\text { Você acredita que conciliar as atividades domésticas e filhos atrapalha no desenvolvimento de carreira, tanto no } \\
\text { sentido acadêmico como profissional? }\end{array}$} \\
\hline Entrevistada 1 & Sim, precisa-se muito do apoio e compreensão do conjugue, da família ao todo. \\
\hline Entrevistada 2 & Acredito sim, pois é muito mais difícil, mas não é impossível, eu consigo realizar... \\
\hline Entrevistada 3 & É possível sim, se organizar o tempo apesar das dificuldades. \\
\hline Entrevistada 4 & $\begin{array}{l}\text { Dificulta sim o desenvolvimento profissional, a mulher acaba tendo de fazer mais opções pela família do } \\
\text { que o homem... }\end{array}$ \\
\hline
\end{tabular}

A somatória destas respostas, com as anteriores, permite perceber a sobrecarga cotidiana das mulheres com suas multitarefas, mesmo que estas venham conseguindo neste percurso histórico conciliá- 
las de forma a conseguir desenvolver-se e alcançar outros espaços. Tal sobrecarga de atividades pode gerar um esgotamento físico e mental como Cavedon et al. (2005) alerta em sua pesquisa. De acordo com as pesquisas realizadas por Lauscher, Rabello e Castells, por muito tempo as empresas pagaram menos pelo mesmo trabalho, distinguindo pelo gênero, e apesar dos avanços, tal prática ainda resiste e sob desconhecimento de muitos. Assim, a equiparação salarial nas questões de gênero é uma das pautas históricas de luta nos movimentos sociais femininos, até atualmente, porém há falta de ciência das próprias mulheres sobre suas desvantagens. Visto isso, questionamos às entrevistadas:

Tabela 6: Profissão com faixa salarial menor do que a dos homens na mesma função.

\begin{tabular}{|l|l|}
\hline Você já exerceu profissão que a faixa salarial foi menor do que a dos homens na mesma função? \\
\hline Entrevistada $\mathbf{1}$ & Ainda não. \\
\hline Entrevistada $\mathbf{2}$ & Não, mas sei que existe. \\
\hline Entrevistada $\mathbf{3}$ & Não porque sempre fui empreendedora. \\
\hline Entrevistada $\mathbf{4}$ & Sim. \\
\hline
\end{tabular}

Ao considerar o tratamento e o respeito às lideranças nas empresas tendo como ponto de partida a questão de gênero, há ainda discriminação e desrespeito às mulheres nestes espaços conforme foi discutido por Gonçalves (2008) e segundo as perspectivas das entrevistadas ao responderem a pergunta a seguir:

Tabela 7: Mulher e um homem exercendo cargos de lideranças x Respeito dos colaboradores.

\begin{tabular}{|l|l|}
\hline $\begin{array}{l}\text { Você acredita que uma mulher e um homem que exercem cargos de lideranças em uma empresa têm o mesmo nível de respeito } \\
\text { de seus colaboradores? }\end{array}$ \\
\hline Entrevistada 1 & Sim, vai depender da postura da mulher em passar segurança ao cargo que exerce. \\
\hline Entrevistada 2 & Infelizmente ainda existe muita diferença, há muito o que melhorar. \\
\hline Entrevistada 3 & Não, há piadas, os homens não aceitam obedecer a ordens femininas, ter uma chefe... \\
\hline Entrevistada 4 & Não. \\
\hline
\end{tabular}

Concluindo a partir das respostas, que há uma diferença no tratamento pelos colaboradores nas relações interpessoais com uma liderança feminina. Pois, como aponta Cunha et al. (2009) e Abramo (2010), devido à estereótipos, para os colaboradores e a sociedade em linhas gerais, há um estranhamento ao ver uma liderança feminina e em permitirem ser liderados por uma mulher, em contextos culturais de que a mulher 'foi projetada para trabalhar no lar'. Levando esse pensamento em consideração, foi questionado nesta pesquisa de campo:

Tabela 8: Barreiras encontradas na rotina de liderança nas organizações.

\begin{tabular}{|l|l|}
\hline \multicolumn{2}{|l|}{ Quais as principais barreiras encontradas na rotina de liderança nas organizações? } \\
\hline Entrevistada 1 & Falta de qualificação e responsabilidade dos funcionários. \\
\hline Entrevistada 2 & Muitas, todos os dias surgem situações e problemas... \\
\hline Entrevistada 3 & Competitividade, as relações interpessoais ao liderar um lugar em que predominam homens... \\
\hline Entrevistada 4 & $\begin{array}{l}\text { Há uma clara discriminação quando a mulher exerce um cargo de chefia, pouco respeito, acredito } \\
\text { que os homens pensam que a mulher não vai dar conta do seu cargo... }\end{array}$ \\
\hline
\end{tabular}

Salientando a adesão feminina a atividade econômica, intelectual e empresarial, apesar de barreiras também culturais, socialmente construídas que reproduzem padrões de dominação e subordinação conforme visto em Gonçalves (2008), há nas pesquisas visibilidade para conquista de em novos espaços de atuação para as mulheres. A partir desse contexto, foi formulada a pergunta da pesquisa:

Tabela 9: Participação da mulher no mercado de trabalho. 


\begin{tabular}{|l|l|}
\hline $\begin{array}{l}\text { Você acredita que a participação da mulher no mercado vem aumentando no decorrer dos anos e com isso diminuindo as } \\
\text { desigualdades? }\end{array}$ \\
\hline Entrevistada 1 & $\begin{array}{l}\text { Sim, a mulher tem mostrado seu potencial, organização e grande capacidade de gerir e liderar pequenas, } \\
\text { médias e grandes empresas. Ganhando assim cada vez mais espaço e quebrando tabus. }\end{array}$ \\
\hline Entrevistada 2 & Com certeza, a mulher vem conquistando seu espaço a cada dia. \\
\hline Entrevistada 3 & $\begin{array}{l}\text { Elas vêm conquistando o mercado de trabalho, já exercem profissões exercidas somente por homens. } \\
\text { Em todas as áreas, por exemplo, na construção civil, a mulher vem sabendo dominar casa, trabalho, } \\
\text { filhos, marido... Então, com isso, estão conseguindo sua independência financeira, inclusive abrir o seu } \\
\text { próprio negócio, própria empresa. Nestes últimos anos vem abrindo muitas empresas administradas } \\
\text { por mulheres... }\end{array}$ \\
\hline Entrevistada 4 & $\begin{array}{l}\text { Sim, a mulher está inserida nas universidades conseguindo cargos de alto nível, contexto que era muito } \\
\text { diferente há décadas atrás... }\end{array}$ \\
\hline
\end{tabular}

A décima pergunta do roteiro de entrevista com o intuito de perceber os aspectos intrínsecos do cotidiano no que diz respeito a discriminação feminina no trabalho pelo simples fato de 'ser mulher'. Segundo Cardoso (2009), a mulher enfrenta novas e velhas formas de discriminação. Dito que, historicamente, foram criados papéis/estereótipos sobre o que é 'ser mulher' e a partir das transformações do contexto social, junto a luta feminina, tornou-se possível a evolução da mulher no mercado de trabalho e em outros campos. 0 aspecto ainda discriminatório na sociedade atual é claramente visível na resposta da entrevistada 3:

Tabela 10: Discriminação da mulher no mercado de trabalho.

\begin{tabular}{|l|l|}
\hline Você já sofreu algum tipo de discriminação no mercado de trabalho? \\
\hline Entrevistada $\mathbf{1}$ & $\begin{array}{l}\text { Sim, pela falta de qualificação. Hoje o mercado requer de nós atributos que nos faz estar sempre } \\
\text { atualizados, precisamos esta qualificados para o cargo em que almejamos. }\end{array}$ \\
\hline Entrevistada $\mathbf{2}$ & Não, mas conheço pessoas que passaram por isto. \\
\hline Entrevistada 3 & $\begin{array}{l}\text { Sim, no meu trabalho informal, como se os homens criassem uma barreira contra a mulher que é } \\
\text { independente, duvidando da nossa capacidade, inclusive no meu caso que trabalho pra mim.... }\end{array}$ \\
\hline Entrevistada 4 & Sim, falta de confiança, reconhecimento... \\
\hline
\end{tabular}

As mulheres conseguiram um avanço significativo e progressivo no âmbito trabalhista, conforme os dados numéricos trazidos por D'Alonso (2008), do aumento da participação feminina nas atividades laborais do Brasil nos últimos anos. A partir da análise de conjuntura, bibliográfica e pesquisa de campo sobre a temática, há ainda desafios pertinentes para reverter as desigualdades salariais e ascensão funcional. Logo, a última pergunta vem salientar esta questão:

Tabela 11: Faixa salarial das mulheres.

\begin{tabular}{|l|l|}
\hline \multicolumn{2}{|l|}{ Na sua percepção a faixa salarial das mulheres é a mesma de homens que exercem a mesma função? } \\
\hline Entrevistada 1 & Não \\
\hline Entrevistada 2 & $\begin{array}{l}\text { Vejo comentários, no meu ambiente de trabalho vejo salários iguais, mas sei que existe essa distinção } \\
\text { em outros espaços. }\end{array}$ \\
\hline Entrevistada 3 & $\begin{array}{l}\text { Com certeza não, essa é outra dificuldade enfrentada pelas mulheres, essa discriminação salarial... } \\
\text { ainda é muito inferior, já houve mudanças mas deve melhorar mais ainda, visto que há salários } \\
\text { diferentes para um mesmo cargo quando é exercido por um homens e mulheres... }\end{array}$ \\
\hline Entrevistada 4 & Infelizmente ainda existe essa diferença salarial. \\
\hline
\end{tabular}

Assim, a evolução da mulher no mercado de trabalho reflete conquistas e luta das mulheres por respeito e igualdade de direitos. A mulher ultrapassou opressões e convive ainda diariamente com discriminação, em razão do gênero, sendo importante salientar, que esta pesquisa demonstrou, nesta discussão, que a mulher vem superando imposições socioculturais que compreendiam estar unicamente como filha, esposa e mãe, hoje, a mesma, pode e assume cargos de liderança e de empreendedora, onde é possível o reconhecimento de sua capacidade laborativa e compensação por seu trabalho. 


\section{CONCLUSÕES}

Este artigo discorreu sobre a visão sócio histórica de construção do feminino para compreensão de questões atuais pertinente ao âmbito social e do trabalho, em uma perspectiva de evolução histórica de conquista femininas que inclusive permite a presença da mulher, hoje, em cargos de liderança, demonstrando capacidades e eficiência. Logo, a partir da pesquisa de campo com mulheres que vivenciam o contexto empresarial contemporâneo, foi possível cumprir o propósito da pesquisa ao destacar como a mulher tem conseguido alcançar novos espaços e lidar com os desafios cotidianos, próprios da questão de gênero, rumo a autonomia e a independência em uma série de aspectos.

Este trabalho destacou as principais barreiras sociais que a mulher teve que vencer no decorrer dos séculos, resultado de uma construção cultural do papel do homem e da mulher que se refere a tratos sociais desiguais de poder entre homens e mulheres. A visão da mulher enquanto líder, quebra paradigmas impostos em épocas anteriores, apesar das contínuas dificuldades de exercer essa liderança atualmente, a mulher vem mostrando sua habilidade de ser gestora de negócios e de sua vida pessoal de forma concomitante. Sendo que um dos pontos de dificuldades pontuados, no decorrer deste trabalho e da vivência das mulheres entrevistadas, é a discriminação, desafio diário para as mulheres em sociedade e no trabalho.

Mesmo diante dos obstáculos pontuados, a mulher se inseriu e desenvolveu em diversos âmbitos sociais, ao conciliar vida doméstica, acadêmica e profissional, o que oportunizou sua inserção em espaços predominantemente masculinos. O mercado de trabalho também está em constante transformação, a mulher superou o papel de subordinada na sociedade, inclusive no trabalho, considerando os exemplos de liderança feminina existentes e a conquista de espaço diante de uma sociedade até então dominada pela força masculina.

A partir do levantamento bibliográfico, para construir uma reflexão sobre aspectos culturais, bem como as transformações que permeiam o cenário atual, no intuito de alcançar os objetivos deste trabalho, foi realizada uma pesquisa em artigos, livros, teses e sites especializados que constituem a base teórica deste trabalho. Considerando as temáticas pertinentes a discussão proposta, construiu-se um roteiro de entrevista em que foi possível obter as informações, no sentido de confirmar as hipóteses norteadoras deste trabalho. Pode-se constatar que a mulher evoluiu muito em suas conquistas, uma delas é a inserção no mercado de trabalho e que ainda há muito que ser conquistado, com base na necessidade constante de transformação, evolução do pensamento social e reconhecimento das capacidades laborativas das mulheres.

A partir das fontes de pesquisa foi possível perceber que há evolução nas conquistas da mulher nos últimos tempos no mercado de trabalho. Porém, ainda é presente em nossa realidade uma condição de desvantagem em relação aos homens, pois continua existindo preconceito, discriminação e desigualdades, inclusive salariais. Fatores estes apontados pelas entrevistadas, que dificultam o cotidiano social e de trabalho destas mulheres nas lideranças. As próximas pesquisas devem reconhecer o duplo aspecto existente na realidade social, pois ao mesmo tempo em que há uma evolução feminina no trabalho e em outros 
âmbitos da vida social como a educação, ainda se reproduzem barreiras culturais que dificultam esta mesma evolução de forma contínua.

\section{REFERÊNCIAS}

ALVES, B. M.. O que é feminismo. São Paulo: Brasiliense, 2007.

ABRAMO, L. W.. A inserção da mulher no mercado de trabalho: uma força de trabalho secundária? Tese (Doutorado em Sociologia) - Universidade de São Paulo, São Paulo, 2007.

ANDRADE, T.. Mulheres no mercado de trabalho: onde nasce a desigualdade?. Consultoria legislativa. Brasília: Câmara dos deputados, 2016.

BARBOSA, A. L. N. H.. Participação feminina no mercado de trabalho brasileiro. Rev. Mercado de trabalho, n.57, 2014.

BAYLÃO, A. L. S.; SCHETTINO, E. M. O.. A inserção da mulher no mercado de trabalho brasileiro. In: SIMPÓSIO DE EXCELÊNCIA EM GESTÃO E TECNOLOGIA, 11. Anais. Rio de Janeiro, 2014

BRUSCHINI, C; LOMBARDI, M. R.. Trabalhadoras brasileiras dos anos 90: mais numerosas, mais velhas e mais instruídas, 2012.

CASTELLS, M. O Poder da Identidade. São Paulo: Paz e Terra, 1999.

CAVEDON, R. N.; GIORDANI, G. C.; CRAIDE, A.. Mulheres trabalhando e administrando espaços de identidade masculina In: ENCONTRO DA ASSOCIAÇÃO NACIONAL DOS PROGRAMAS DE PÓS-GRADUAÇÃO EM ADMINISTRAÇÃO, 29. Anais. Brasília: ANPAD, 2005.

CERVO, A. L.; BERVIAN, P. A.. Metodologia Cientifica. 5 ed. São Paulo: Prentice Hall, 2002.

CHIAVENATO, I.. Gestão de Pessoas: e o novo papel dos recursos humanos nas organizações. 3 ed. Rio de Janeiro: Elsevier, 2008.

CUNHA, G.; FUENTES, F.. Mulheres, trabalho e globalização: Gênero, como determinante nos padrões globais de desigualdade. Revista Ártemis, v.4, 2006.

DALONSO, G. L.. Trabalhadoras brasileiras e a relação com o trabalho: trajetórias e travessias. Psicol. Am. Lat., n.15, 2008.

GARCIA, L. S.; CONFORTO, E.. A inserção feminina no mercado de trabalho urbano brasileiro e renda familiar. 2012.

GIL, A. C.. Como elaborar projetos de pesquisa. 4 ed. São Paulo: Atlas, 2008.

GOMES, A. F.. O outro no trabalho: mulher e gestão. Revista de Gestão USP, São Paulo, v.12, n.3, p.1-9, 2005.
GONÇALVES, B. D.. Identidade feminina e a inserção no mundo do poder: uma análise psicopolítica. Curitiba: Juruá, 2008.

HIRATA, H; KERGOAT, D.. Novas configurações da divisão sexual do trabalho. Cad. Pesqui., v.37, n.132, p.595-609, 2007.

KANAN, L. A.. Poder e liderança de mulheres nas organizações de trabalho. Revista O\&S, Salvador, v.17, n.53, p.243-257, 2010

KAUFMANN, J. C.. A entrevista compreensiva: Um guia para pesquisa de campo. Petrópolis: Vozes; Maceió: Edufal, 2013.

LAKATOS, E. M.; MARCONI, M. A.. Fundamentos de metodologia cientifica. 4 ed. São Paulo: Atlas, 2001.

LAUSCHNER, M. C. X. G. S.. Os movimentos feministas: família $x$ trabalho. In: ENCONTRO REDOR, 16. Anais. Manaus: Edua, 2010. p.154-156

MAIO, C. A.; ARAUJO, E. A. S.; HAMZAGIC, M.; SILVA, J. L. G. Mulheres na liderança: a evolução das mulheres no mercado de trabalho. In: ENCONTRO LATINO AMERICANO DE INICIAÇÃO CIENTÍFICA, 16 E ENCONTRO LATINO AMERICANO DE PÓS-GRADUAÇÃO, 12. Anais. São José dos Campos: Universidade do Vale do Paraíba, 2012.

MALHOTRA, N. K.. Pesquisa de marketing: uma orientação aplicada. 4 ed. Porto Alegre: Bookman, 2006.

MINAYO, M. C. S.. Pesquisa social: teoria, método e criatividade. Petrópolis: Vozes, 2012.

NEVES, M. A.. Anotações sobre trabalho e gênero. Cadernos de Pesquisa, São Paulo, v.43, n.149, p.404-421, 2013.

NUZZI, V.. Pesquisa sobre mulheres no mercado de trabalho mostra alguns avanços e velhos problemas. São Paulo: RBA, 2011.

OIT BRASIL. Igualdade de gênero e raça no trabalho: avanços e desafios. Brasília: OIT, 2010.

PASSOS, L.; GUEDES, D. R.. Participação feminina no mercado de trabalho e a crise de cuidados da modernidade: conexões diversas. Planejamento e Políticas Públicas, n.50, 2017.

PINHEIRO, J. C.. Trabalho feminino do Brasil: A análise da evolução da participação da mulher no mercado de trabalho (1950-2010). Monografia (Graduação em Economia) Universidade Federal do Rio Grande do Sul, Porto Alegre, 2012.

RABELLO, J. R.. Evolução da participação feminina no mercado de trabalho. São Paulo: FEMA, 2013. 
RODRIGUES, A. R. E.. A mulher no mercado de trabalho e o princípio da não descriminação. Monografia (Graduação) Faculdades Integradas do Brasil, 2010.

SILVA, G. C. C.. A mulher e sua posição na sociedade: da antiguidade aos dias atuais. Rev. SBPH., Rio de Janeiro, v.8, n.2, p.65-76, 2005

SIMÕES, F. I. W.; HASHIMOTO, F.. Mulher, mercado de trabalho e as configurações familiares do século XX. Revista Vozes dos Vales, v.1, n.2, 2012.
SPRICIGO, C.. Gestão empresarial e ascensão feminina: estudo de caso numa empresa da região sul do Brasil. In: Seminário Nacional de Serviço Social, Trabalho e Políticas Sociais, 2. Anais. Florianópolis: Universidade Federal de Santa Catarina, 2017.

TREVISAN. K.. Presença feminina no mercado de trabalho aumenta em 2012, diz IBGE. G1, 2014.

A CBPC - Companhia Brasileira de Produção Científica (CNPJ: 11.221.422/0001-03) detém os direitos materiais desta publicação. Os direitos referem-se à publicação do trabalho em qualquer part do mundo, incluindo os direitos às renovações, expansões e disseminações da contribuição, bem como outros direitos subsidiários. Todos os trabalhos publicados eletronicamente poderão posteriormente ser publicados em coletâneas impressas sob coordenação da Cognitionis Publishing, da Companhia Brasileira de Produção Científica e seus parceiros autorizados. Os (as) autores (as) preservam os direitos autorais, mas não têm permissão para a publicação da contribuição em outro meio, impresso ou digital, em português ou em tradução. 